Int. J. Electrochem. Sci., 11 (2016) $8486-8498$

\title{
A Novel Nonenzymatic Hydrogen Peroxide Electrochemical Sensor Based on Facile Synthesis of Copper Oxide Nanoparticles Dopping into Graphene Sheets@Cerium Oxide Nanocomposites Sensitized Screen Printed Electrode
}

\author{
Guo-wen $\mathrm{He}^{1}$, Jian-qing Jiang ${ }^{2, *}$, Dan $\mathrm{Wu}^{1}$, Yi-lan $\mathrm{You}^{1}$, Xin Yang ${ }^{3,4, *}$, Feng Wu ${ }^{3,4}$, Yang-jian $\mathrm{Hu}^{3,4}$ \\ ${ }^{1}$ College of Chemical and Environmental Engineering, Hunan City University, Yiyang, 413000, P.R. \\ China; \\ ${ }^{2}$ School of Civil Engineering, Hunan City University, Yiyang, 413000, P.R. China; \\ ${ }^{3}$ Huaihua Key Laboratory of Functional Inorganic\&Polymeric Materials, College of Chemistry and \\ Materials Engineering, Huaihua University, Huaihua 418000, P.R. China; \\ ${ }^{4}$ Key Laboratory of Rare Earth Optoelectronic Materials\&Devices, College of Chemistry and \\ Materials Engineering, Huaihua University, Huaihua 418000, P.R. China; \\ *E-mail: zhongyipp@163.com; 01yangxin@163.com
}

doi: $10.20964 / 2016.10 .34$

Received: 23 April 2016 / Accepted: 8 August 2016 / Published: 6 September 2016

\begin{abstract}
A novel electrochemical sensor for nonenzymatic hydrogen peroxide $\left(\mathrm{H}_{2} \mathrm{O}_{2}\right)$ detecting based on facile synthesis of copper oxide $(\mathrm{CuO})$ nanoparticles dopping into graphene sheets@cerium oxide nanocomposites sensitized screen printed electrode (SPE) was fabricated. $\mathrm{CuO}$ nanoparticles were dopped into $\mathrm{GS} @ \mathrm{CeO}_{2}$ nanocomposites via a facile solvothermal process. X-ray powder diffractometer (XRD) combines with fourier transform infrared spectroscopy (FTIR) were used to characterize the composition of $\mathrm{GS} @ \mathrm{CeO}_{2}-\mathrm{CuO}$ nanocomposites. Electrochemical impedance spectroscopy (EIS) was utilized to study the interfacial properties as well as scanning electron microscopy (SEM) was employed to characterize the morphologies of different electrodes. The electrochemical properties of electrochemical sensor were investigated by cyclic voltammetry (CV) and chronoamperometry (i-t curve) methods. After all experimental parameters were optimized, the GS@ $\mathrm{CeO}_{2}-\mathrm{CuO}$ hybrid nanomaterials modified SPE (SPE $\mid \mathrm{GS} @ \mathrm{CeO}_{2}-\mathrm{CuO}$ ) showed a good performance towards the electrocatalytic reduction of $\mathrm{H}_{2} \mathrm{O}_{2}$. A wide linear detection range (LDR) of $\mathrm{CV}$ peaks from $5.0 \times 10^{-3} \mathrm{mM}$ to $18.0 \mathrm{mM}(R=0.9994)$ and a low limit of detection (LOD) of $2.1 \times 10^{-3}$ $\mathrm{mM}(S / N=3)$ was achieved. The proposed electrochemical sensor was quick, selective, sensitive, simple, stable and reliable to quantitative determination of trace $\mathrm{H}_{2} \mathrm{O}_{2}$ in real samples.
\end{abstract}

Keywords: Copper oxide; Graphene sheets@ cerium oxide; Screen printed electrode; Nonenzymatic; Hydrogen peroxide. 


\section{FULL TEXT}

(C) 2016 The Authors. Published by ESG (www.electrochemsci.org). This article is an open access article distributed under the terms and conditions of the Creative Commons Attribution license (http://creativecommons.org/licenses/by/4.0/). 